\title{
Position evaluation of ex-core neutron flux measurement in new type graphite reactors
}

\author{
Eva Vilimova ${ }^{1 *}$, Tomas Peltan ${ }^{1,2}$, and Radek Skoda ${ }^{3}$ \\ ${ }^{1}$ University of West Bohemia, Faculty of Electrical Engineering, Univerzitni 8, 30100 Pilsen, Czechia \\ ${ }^{2}$ Research Center Rez, Hlavni 130, Rez, 25068 Husinec, Czechia \\ ${ }^{3}$ Czech Institute of Informatics, Robotics and Cybernetics, Jugoslavskych partyzanu 1580/3, 16000 Prague, Czechia \\ *vilimova@fel.zcu.cz
}

\begin{abstract}
Several concepts of new reactors use graphite. Some of them use graphite as a moderator, some of them as a reflector. There are at least two concepts of these graphitetype reactors under development in the Czech Republic. Both reactors use graphite as the reflector. An in-core measurement might be impossible to use because of various reasons, for instance, high temperature or aggressive environment. Therefore, this article focuses on ex-core neutron flux measurement system placed in the graphite reflector and the optimization of ex-core detector position. A set of experiments were performed at LR-0 reactor. The LR-0 is a light water reactor with a well-defined neutron field, which can be used for different material insertion tests and testing of its influence on criticality. Several modifications of LR-0 cores were modelled in Monte Carlo codes Serpent and KENO. A set of calculations were performed for verification of the criticality and neutron flux course in the reactor core and graphite reflector. Further investigation was focused on the influence of the presence of a graphite reflector on the neutron distribution in the reactor core. The LR-0 graphite experiments were also used to verify the calculations. Based on the results of this article, the optimal position of ex-core detectors in the graphite reflector is proposed.
\end{abstract}

Keywords-ex-core measurement, neutron flux, graphite reflector, Serpent, KENO

\section{INTRODUCTION}

$\mathbf{I}_{\mathrm{n}}^{\mathrm{N}}$ $\mathrm{N}$ the context of global interest in small modular reactors and new $4^{\text {th }}$ generation reactors, the Czech Republic thinks about their utilization in its own energy sector. Czech researchers propose a few designs of small reactor concepts. One of the main nuclear core components of these concepts is graphite either as a moderator or as a reflector.

In addition to the power reactors, all small reactor concepts need to be equipped with neutron flux instrumentation to control reactor power and ensure reactor safety functions. Hence, the appropriate neutron flux instrumentation should be designed and implemented in the concept. The neutron flux can be measured by in-core detectors or by ex-core detectors. In practice, the combination of both methods is usually used. This paper focuses mainly on ex-core neutron flux instrumentation in reactors with the graphite reflector. The research will be applied to the molten salt modular reactor.

Reference [1] discusses parameters and operating conditions for $4^{\text {th }}$ generation reactors and also the challenges of positioning of the neutron flux measurement. This work presents the following research of the optimal detector position in the graphite reflector. The positioning of the detectors has to be determined with respect to the axial and radial neutron flux distribution and the whole reactor core design.

Findings from the research in reference [1] were applied to the research reactor LR-0 in the Research Centre Rež. The research reactor LR-0 is a pool-type light-water reactor with zero power, which serves mainly for measuring neutronphysical characteristics of VVER type reactors. To design the appropriate neutron flux apparatus, the graphite reflector and its behavior in neutron flux were investigated. A graphite prism was prepared and a set of experiments were carried out in the LR-0 reactor. These experiments serve as a source of experimental data for the validation of neutron flux models, which were created in the Monte Carlo codes Serpent and SCALE-KENO [2-3]. At the same time, these experiments will serve for the development of the new ex-core measurement system and validation of its properties. Thus, the performed calculations investigate the optimal position of the ex-ore detectors in the graphite prism and a neutron flux distribution.

\section{EXPERIMENTS AND MODELS}

\section{A. Critical experiments in reactor $L R-O$}

Recently, four critical experiments have been performed by the expert team at the LR-0 reactor. The reactor LR-0 is an experimental light-water-moderated zero-power reactor, originally designed for research of the VVER-1000 and VVER-440 type cores, spent-fuel storage lattices and benchmark experiments. The reactor reaches criticality by changing the moderator level. These experiments have been evaluated and the Research center Řež has provided the data for validation of created models.

The first experiment includes two variants with different insertions: CASE 1A and CASE 1B, as shown in Fig. 1. The core consists of six shortened VVER-1000 fuel assemblies with enrichment $3.28 \%, 3.29 \%$, and $3.30 \%$ of ${ }^{235} \mathrm{U}$. An experimental module, where the insertions are installed, stands in the center of the six fuel assemblies. In CASE 1A, the central module is empty and filled with dry air. In CASE 1B, the central experimental module contains six graphite blocks. These 
experiments are proposed as benchmark experiments. For CASE 1A, the critical height of the moderator $H_{c r}$ is $44.381 \mathrm{~cm}$. In CASE 1B, the configuration became critical at the moderator level $H_{c r}=55.600 \mathrm{~cm}$. [4], [5]

The second core configuration, CASE 2 in Fig. 1, examines graphite as the reflector. Twelve graphite blocks surround the reactor core, which is the same as the core in CASES 1A and 1B. The center of the reactor core is filled with dry air. This case represents the reference core configuration with the graphite reflector, where the ex-core detectors will be situated. In this critical experiment, the critical moderator level $H_{c r}$ is $41.661 \mathrm{~cm}$. [6]

The last critical experiment composes of seven graphite insertions as a central reflector and twelve radial fuel assemblies enriched to $3.6 \%$ and $3.59 \%$ of ${ }^{235} \mathrm{U}$. The critical height of the moderator is $39.940 \mathrm{~cm}$ in this case. [7]

\section{B. Models and calculations}

All criticality calculations and neutronic analyses were done in two Monte Carlo calculation codes. One of the codes is Serpent [2] developed by VTT Technical Research Centre of Finland. The second calculation code is SCALE-KENO developed and maintained by Oak Ridge National Laboratory [3]. All cases were modeled in accordance with the corresponding benchmark specifications, for instance void replaces the dry air in the reactor.

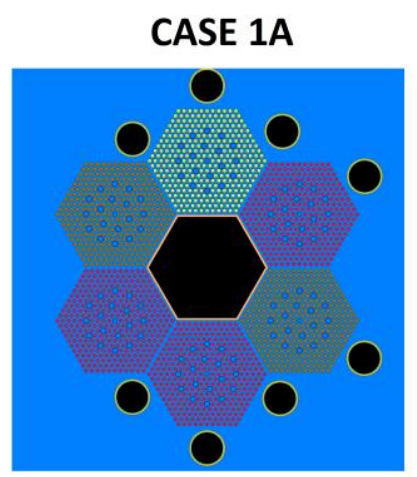

CASE 2

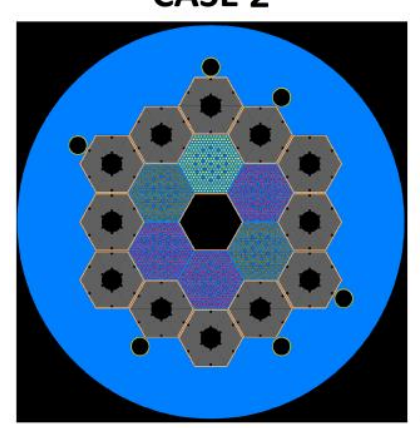

Fig. 1. The core configurations performed at the LR-0 reactor. CASE $1 \mathrm{~A}$ and CASE 1B, CASE 2 and CASE 3.

The Serpent 2.1.31 code was used as a reference for neutronic calculations as criticality and neutron spectra. The neutron transport in criticality calculations was simulated with 50000 neutrons per cycle and 10000 active cycles (100 inactive cycles). The neutron spectrum analyses in the core center ran with 500000 neutrons per cycle in 50000 active cycles with 100 inactive cycles because of a very fine energy group structure. The energy group structure includes 640 groups with a total energy span of $10^{-10} \mathrm{MeV}$ to $20 \mathrm{MeV}$. This group structure has 45 energy groups per energy decade below $1 \mathrm{MeV}$ and a group width of $100 \mathrm{keV}$ above $1 \mathrm{MeV}$ [8]. The dimensions of the modelled detector in the center are $6 \times 6 \mathrm{~cm}$, which corresponds with the stilbene detector used in real experiments.

For the analyses of the radial neutron spectrum, the predefined 7-group CASMO energy structure was used. The energy structure was chosen taking into account the microscopic cross-section of the graphite, which is smooth in the desired thermal energy. For this reason, the calculations were carried out with 200000 neutrons in 50000 histories with 100 inactive cycles.

In addition, all four critical configurations were created in the code SCALE-KENO. The criticality calculation results from KENO serve as a code-to-code comparison. For the neutron transport simulation, KENO used 50000 neutrons per generation in 5000 generations and 100 inactive generations.

TABLE 1: COMPARISON OF CRITICALITY CALCULATIONS IN SERPENT $(\sigma=0.00004)$ AND SCALE-KENO $(\sigma=0.00005)$

\begin{tabular}{l|c|c|c|c}
\hline \hline ENDF/B-VII.1 & $\begin{array}{c}\text { Serpent } \\
k_{\text {eff }}\end{array}$ & $\begin{array}{c}\text { KENO } \\
k_{\text {eff }}\end{array}$ & $\begin{array}{c}\text { Serpent- } \\
\text { KENO [pcm] }\end{array}$ & $H_{c r}[\mathrm{~cm}]$ \\
\hline CASE 1A & 1.00056 & 0.99991 & 50 & 55.600 \\
CASE 1B & 1.00077 & 1.00057 & 20 & 44.381 \\
CASE 2 & 1.00295 & 1.00326 & -31 & 41.661 \\
CASE 3 & 1.00311 & 1.00365 & -54 & 39.940 \\
\hline \hline
\end{tabular}

All calculations were performed with the ENDF/B-VII.1 nuclear data library [9]. The uncertainty of the multiplication factor $k_{\text {eff }}$ is $\sigma=0.00004$ for Serpent and $\sigma=0.00005$ for KENO.

Table 1 shows that the results obtained from Serpent and KENO are in good agreement with each other. Note that CASE 1B and CASE 2 indicate the effect of the position of the graphite reflector in the reactor core. Despite the different fuel configurations in CASE 3, there is an obvious indirect dependency of the critical height of the moderator level and the amount of graphite in all cases.

\section{NEUTRON SPECTRA AND FLUX DISTRIBUTION}

\section{A. Neutron spectra in the core center}

Gradual insertion of the graphite blocks inside or outside the fuel geometry enables an investigation of the influence of graphite on the neutron spectrum in the core center by comparison of four neutron spectra in the core center in all cases. This comparison shows Fig. 2. In this figure, the effect of gradual enlargement of the central reflector is clearly visible in CASE $1 \mathrm{~B}$ and CASE 3.

Note that the number of thermal neutrons in CASE 3 is much higher than in the other cases and the neutron spectrum is flat at higher energies, the neutrons are very well thermalized. On the other hand, the difference between CASE 1A and CASE 2 is negligible, the contribution of the reflector to the detector response is very small. 


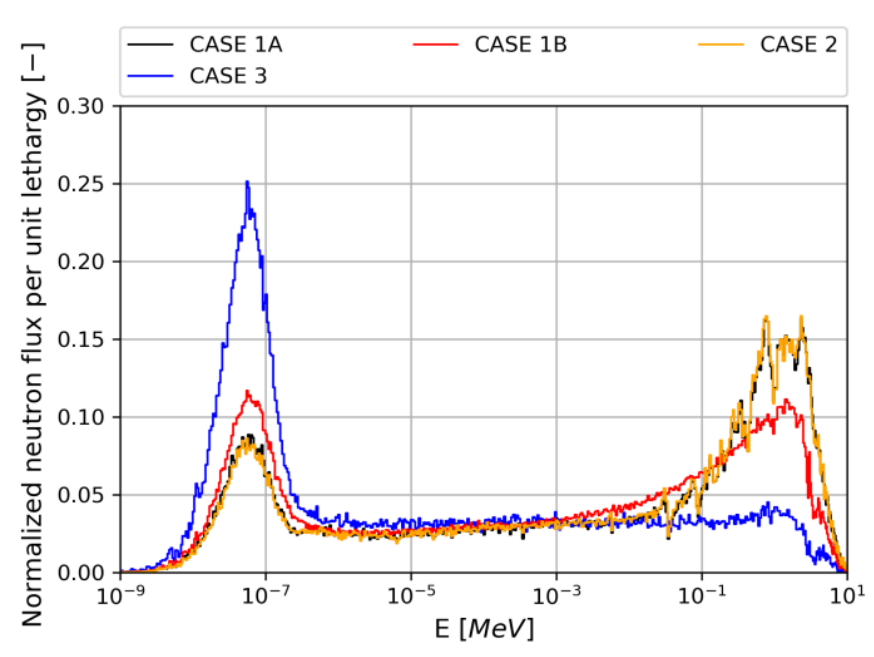

Fig. 2. Neutron spectra in the core center in all cases.

\section{B. Neutron spectra in the position of the reflector}

To evaluate the optimal position of ex-core detectors in the graphite reflector, the neutron flux distribution profile was studied in the core configuration called CASE 2. This core configuration is most similar to the reactor core, where the neutron detection system under development will be tested. The detectors score in the width of the graphite block, which is $25 \mathrm{~cm}$ on the left-hand side of the reflector in the negative $\mathrm{x}$-axis direction. The calculated neutron flux profile in the radial direction shows Fig. 3. The flux of thermal neutrons appears to be constant, or rather it decreases very slowly through the graphite reflector. For comparison, the radial neutron flux profile was calculated also in CASE 1A without graphite i.e., in light water (Fig. 4). The detectors score in the same position as in CASE 2.

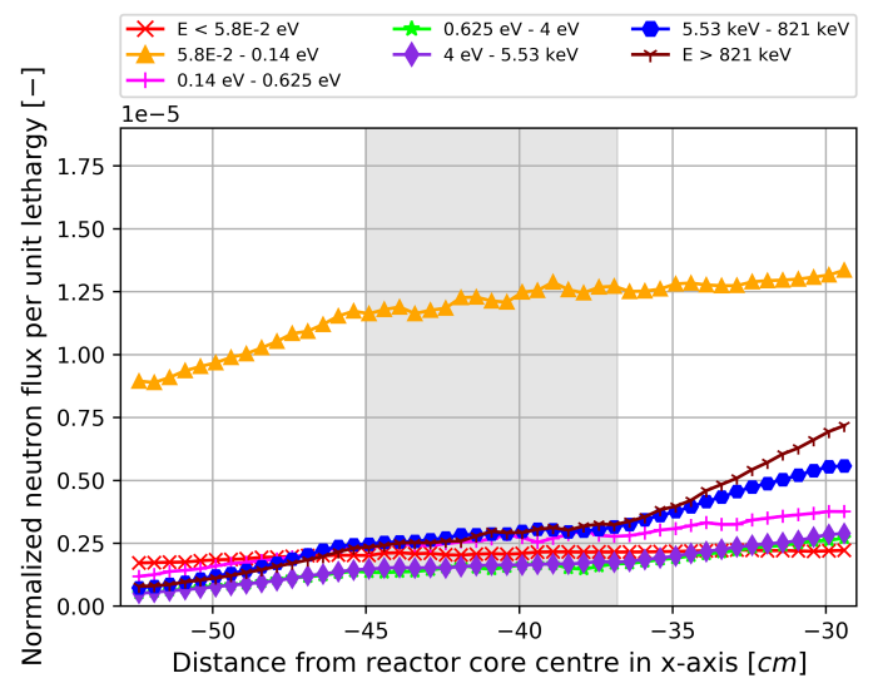

Fig. 3. Neutron flux profile in the graphite reflector-CASE 2. The 7-group structure, ENDF/B-VII.1 [6]

\section{Ex-core detector position evaluation}

Due to very high slowing-down power of light water, the thermal reflector peak is sharp, clearly visible and obvious and

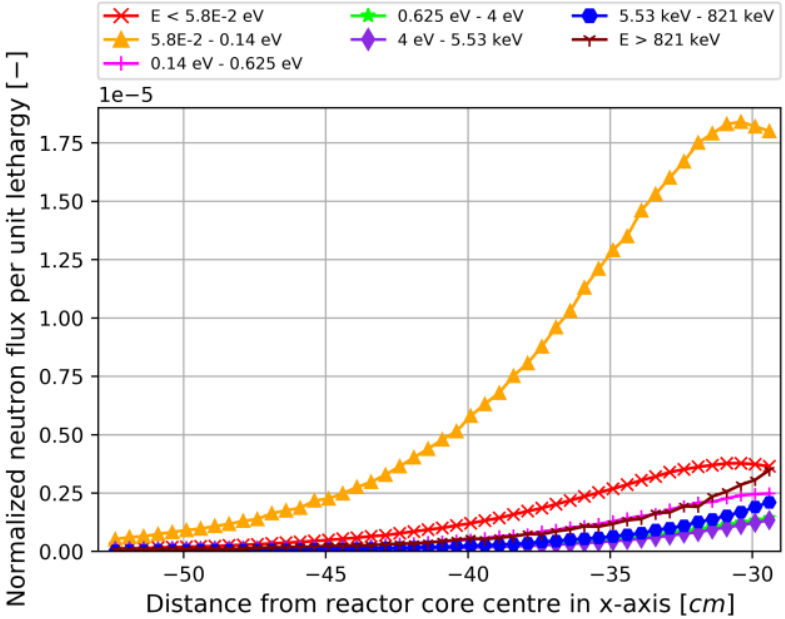

Fig. 4. Neutron flux profile in light water - CASE 1A. The same position of the detectors as in the CASE 2. 7-group structure, ENDF/B-VII.1 [6]

it locates very close to the fuel. The thermal neutron flux in the graphite reflector is comparatively flatter, when compared to light water. Moreover, there is an obvious effect of the center holes in the graphite blocks (gray background in Fig. 3), which slightly disturbs the neutron distribution in the graphite reflector, and the reflector peak is difficult to recognize.

The results show that the optimal position of the ex-core detector is not as strictly defined as for a light-water reflector. The position in the graphite reflector could be adapted to detector requirements such as a temperature limit or maximal neutron flux. However, the optimal position of the ex-core detectors, in terms of good neutron flux response of the detectors, is in the reflector peak, which is not clearly visible in the results.

Regarding the obtained results, another experiment will be carried out. This experiment will have the same reactor core arrangement as in CASES 1A, 1B, and 2, but the width of the graphite reflector will be doubled and the holes in the graphite block will be plugged with graphite cylinders. This new experiment is expected to show better results in terms of a clearer neutron flux profile in the reflector and, hopefully, hint of the reflector peak. This will help to determine the ex-core detectors' position more precisely.

\section{CONCLUSIONS}

This work focuses on the design of an ex-core measuring system for the new small reactor concepts with a graphite reflector. These reactor concepts need to be equipped with a neutron flux instrumentation to control the reactor power and to ensure the safety functions. Hence, a neutron flux detection system should be designed, so this work presents the research of an optimal detector position in the graphite reflector.

A set of experiments were performed at research reactor LR-0. The critical levels of the moderator, which were obtained from experimental data, were used to model these core arrangements in Serpent and SCALE-KENO. Then, the neutron properties of the graphite were studied to determine the optimal position of the ex-core detectors in the graphite reflector. The study of graphite insertions in different reactor core geometry 
showed a noticeable effect on neutron spectra in the centers of the core.

Optimal position of the ex-core detectors should be specified from the radial neutron distribution in the graphite reflector. However, the calculated results of the radial neutron distribution do not show the exact position of the detectors, so another experiment with a double-width reflector will be carried out in future research to determine the position more accurately.

\section{ACKNOWLEDGMENTS}

The research has been supported by the TK01030103 Ex-core Neutron Flux Measurement for the $4^{\text {th }}$ Generation Nuclear Reactors project and by project no. SGS 2021-018 granted by Technology Agency of the Czech Republic (TA CR) and by Ministry of Education Youth and Sports of Czech Republic.

\section{REFERENCES}

[1] A. Fořtová, R. Škoda, and J. Závorka, "Ex-core neutron flux monitoring system in graphite prism for gen. IV Reactors," in Proc. ICONE19, Track 16, Tsukuba, Japan, 2019, doi: 10.1299/jsmeicone.2019.27.1627.

[2] J. Leppänen, M. Pusa, T. Viitanen, V. Valtavirta, and T. Kaltiaisenaho, "The Serpent Monte Carlo code: Status, development and applications in 2013," Ann. Nucl. Energy, vol. 82, pp. 142-150, 2015, doi: 10.1016/j.anucene.2014.08.024.

[3] W. A. Wieselquist, L. A. Lefebvre, and M. A. Jessee, "SCALE Code System.” Oak Ridge National Laboratory, Oak Ridge, Tennessee, 2020.

[4] M. Košt’ál, V. Rypar, E. Losa, M. Schulc, E. Novák "VVER-1000 Physics Experiments Hexagonal Lattices (1.275 cm Pitch) of Low Enriched U(3.3 wt.\% U235)O2 Fuel Assemblies in Light Water with Graphite and Fluoride Salt Insertions in Central Assembly." IRPhE benchmarks database (2016)

[5] M. Košt’ál, M. Schulc, E. Losa, J. Šimon, N. Burianová, et al, “A reference neutron field for measurement of spectrum averaged cross sections," Ann. Nucl. Energy, vol. 140, $2020 \quad$, ISSN 0306-4549, doi: 10.1016/j.anucene.2019.107119.

[6] T. Peltan and M. Koštál, "Study of reflection properties of silica sand," in 2020 ANS Virtual Winter Meeting, 2020, vol. 123, pp. 1308-1311, doi: 10.13182/T123-33334.

[7] T. Czakoj, E. Losa, and M. Košt’ál, "Design of a special core for large graphite insertion studies in the LR-0 reactor," in PHYTRA4 - Fourth Int. Conf. Phys. Technol. React. Appl., pp. 238-249, Marrakech, Morocco, September 17-19, 2018.

[8] W.L. Zijp, H.J. Nolthenius, G.C.H.M. Verhaag "CROSS-SECTION LIBRARY DOSCROS84 (in a 640 group structure off the SAND-II type)," Netherlands Energy Research Foundation ECN, vol. 84, October, 1984 .

[9] M. B. et al. Chadwick, "ENDF/B-VII.1: Nuclear Data for Science and Technology: Cross Sections, Covariances, Fission Product Yields and Decay Data," Nucl. Data Sheets, vol. 112, 2011. 